\title{
Fenologia e características físico-químicas de frutos de abacateiros visando à extração de óleo
}

\author{
Phenology and physical and chemical characterization of avocado fruits for oil extraction
}

\author{
Marcelo Caetano Oliveira ${ }^{\mathrm{I}}$ Rafael Pio $^{\mathrm{I}^{*}}$ José Darlan Ramos $^{\mathrm{I}}$ Luiz Carlos Oliveira Lima \\ Moacir Pasqual ${ }^{I}$ Verônica Andrade Santos ${ }^{I}$
}

RESUMO

O abacateiro é uma frutífera altamente produtiva que possui diversas cultivares, as quais apresentam grande variação quanto à época de produção de frutos e quanto ao teor de óleo na polpa. Estudos têm indicado que o óleo de abacate assemelha-se ao azeite de oliva e pode ser empregado tanto na indústria de cosméticos como no setor alimentício. O objetivo deste trabalho foi avaliar as características fenológicas, físicoquímicas em cultivares de abacateiro nas condições das terras altas da serra Mantiqueira em São Bento do Sapucaí - SP, visando à extração de óleo. As avaliações foram efetuadas nas cultivares 'Ouro Verde', 'Wagner', 'Campinas', 'Paulistinha', 'Fuerte', 'Pedroso', 'Margarida', 'Hass', 'Fortuna', 'Quintal' e 'Reis'. Foram avaliadas as características fenológicas nos ciclos 2008/09 e 2009/10, diâmetro longitudinal e transversal, percentagens de polpa, casca e caroço em relação à massa total, composição centesimal, além do perfil dos principais ácidos graxos presentes no óleo bruto extraído das cultivares ricas em lipídeos. Os resultados indicam que o periodo de florescimento variou de agosto a novembro e o de colheita de julho a novembro, sendo a cultivar 'Ouro Verde' a mais precoce e Fuerte, Campinas e Hass as mais tardias. Paulistinha e Reis apresentaram frutos de maior diâmetro longitudinal, sendo que Paulistinha se destacou com a maior porcentagem de polpa. Os maiores teores de lipídeos na polpa foram obtidos nas cultivares 'Fuerte' e 'Hass', com predomínio do ácido graxo oleico nas amostras analisadas.

Palavras-chave: Persea Americana, cultivares, ácidos graxos.

\section{ABSTRACT}

Avocado is a very productive plant. It has several cultivars that present great variation on time of fruit production and oil content in the pulp. Studies have indicated that the avocado oil is similar to olive oil, and can be used in cosmetics and also for human consumption. The objective of this study was to evaluate the phenological characteristics and fruit physicochemical conditions in avocado cultivars from the highlands of Serra da Mantiqueira in São Bento do Sapucaí - SP aiming oil extract. The evaluations were conducted on the cultivars 'Ouro Verde', 'Wagner', 'Campinas', 'Paulistinha', 'Fuerte', 'Pedroso', 'Margarida', 'Hass', 'Fortuna', 'Quintal' and 'Reis'. Were evaluated the phenological characteristics in 2008/09 and 2009/10 cicles, longitudinal and transverse diameter, percentage of pulp, peel and seed against to the total mass, centesimal composition and main acids present in the crude oil extracted from cultivars rich in lipids. Results indicate that the flowering period ranged from August to November and harvesting from July to November, the cultivar 'Ouro Verde' was the earliest and Fuerte, Campinas and Hass were more delayed. Paulistinha and Reis fruit had higher longitudinal diameter. Paulistinha stood out with the highest percentage of pulp. The greatest concentration of lipids in the pulp were obtained in cultivars 'Fuerte' and 'Hass' with predominance of oleic acid in the samples.

Key words: Persea americana, varieties, fatty acids.

\section{INTRODUÇÃO}

O Brasil produz cerca de 140 mil toneladas de abacates em uma área cultivada de 9.453ha, sendo os estados de São Paulo e Minas Gerais os maiores produtores da fruta, com aproximadamente $60 \%$ da área cultivada e $70 \%$ da produção nacional. O Estado de São Paulo apresenta uma produtividade média em torno de $21 \mathrm{t} \mathrm{ha}^{-1}$ e Minas Gerais $13 \mathrm{t} \mathrm{ha}^{-1}$ (IBGE, 2012).

No Brasil, os frutos do abacateiro são consumidos ao natural ou utilizados no processamento

'Departamento de Agricultura, Universidade Federal de Lavras (UFLA), CP 3037, 372000-000, Lavras, MG, Brasil. E-mail: rafaelpio@dag.ufla.br. *Autor para correspondência

"Departamento de Ciência dos Alimentos, UFLA, Lavras, MG, Brasil. 
industrial, na fabricação de doces ou produtos cosméticos. Outra opção seria a extração do óleo da polpa, visando a sua utilização para a alimentação, devido as suas propriedades nutricionais. $\mathrm{O}$ óleo de abacate é rico em $\beta$-sitosterol e ácido oleico, uma gordura insaturada utilizada como coadjuvante no tratamento de hiperlipidemias, assemelhando-se em muitos aspectos ao azeite de oliva (SALGADO et al., 2008). Estudos anteriormente realizados com algumas cultivares mostraram variação entre 5 a $30 \%$ nos teores de lipídeos na polpa. Assim, cultivares que apresentem altos teores de lipídeos na polpa poderão constituir-se em matéria-prima importante para obtenção de óleo (TANGO et al., 2004; SALGADO et al., 2008).

Devido às flores do abacateiro apresentarem dicogamia protogínica, em que não há sincronismo na maturidade dos órgãos masculinos e femininos, as cultivares são divididas em dois grupos (A e B), por isso se recomenda o plantio intercalado de cultivares dos diferentes grupos na mesma área, as quais floresçam na mesma época, assegurando, assim, uma polinização eficiente (FALCÃO et al., 2001). As fenofases, bem como a época de produção dos frutos, podem variar em função das coordenadas geográficas e microclima local (SENTELHAS et al., 1995), influenciando inclusive no teor de óleo.

Sendo assim, a determinação das fases fenológicas e a determinação de cultivares produtoras de frutos com qualidade superior e alto teor lipídico seria fundamental, visando à ampliação das áreas produtoras de abacate e o estímulo para a produção de frutos destinados à extração de óleo. Com base no exposto, o presente trabalho teve como objetivo avaliar as características fenológicas, físico-químicas em cultivares de abacateiro oriundos das terras altas da Mantiqueira, visando à extração de óleo..

\section{MATERIAL E MÉTODOS}

A coleta de dados foi efetuada na coleção de abacateiros mantida no Núcleo de Produção de Mudas de São Bento do Sapucaí-SP, pertencente à Coordenadoria de Assistência Técnica Integral do estado de São Paulo (CATI), microrregião das terras altas da serra da Mantiqueira, entre o período de janeiro de 2008 a dezembro de 2010. O local situase a $22^{\circ} 41^{\prime}$ de latitude Sul e $45^{\circ} 44^{\prime}$ de longitude Oeste, a uma altitude média de 903 metros. O clima de São Bento do Sapucaí é classificado como Cwb subtropical de altitude. A temperatura média anual situa-se em torno de $18^{\circ} \mathrm{C}$ e precipitação entre 1.600 a $1.800 \mathrm{~mm}$. As variações climáticas que ocorreram durante o período de avaliação fenológica e produtiva encontram-se nas figuras 1 e 2 . As cultivares utilizadas nas avaliações foram: 'Ouro Verde', 'Wagner', 'Campinas', 'Paulistinha', 'Fuerte', 'Pedroso', 'Margarida', 'Hass', 'Fortuna', 'Quintal' e 'Reis'. As plantas estão dispostas em blocos de oito plantas e no espaçamento $7 \times 7 \mathrm{~m}$, com idade de sete anos.

Para a caracterização fenológica, utilizou-se o delineamento em blocos ao acaso, com 13 tratamentos (cultivares), quatro blocos e duas plantas por parcela. Nas safras de 2008/09 e 2009/10, registraram-se as seguintes características fenológicas: início da emissão das brotações, início da floração (5\% flores abertas), plena floração ( $70 \%$ das flores abertas) e final de floração ( $95 \%$ ou mais das flores abertas), início da frutificação ( $5 \%$ de frutos fixados), início e final colheita. Para a determinação dessas porcentagens, foram marcados quatro ramos aleatórios por planta, dos quais se contou o número total de flores e frutos e posteriormente o número de flores abertas e frutos fixados a cada dois dias, para então calcular-se as referidas porcentagens. No final, calculou-se o período de florescimento, frutificação e colheita.

Na segunda safra de avaliação (2009/10), foram coletados frutos maduros das onze cultivares de forma aleatória, em um total de 40 frutos por cultivar. Os frutos foram transportados imediatamente para o laboratório de pós-colheita do Departamento de Ciência dos Alimentos da UFLA e foram divididos em quatro repetições, contento dez frutos cada, adotando-se o delineamento inteiramente casualizado, para as seguintes avaliações: diâmetro longitudinal e transversal dos frutos, percentagens de polpa, casca e caroço em relação à massa total e a composição centesimal (porcentagem de umidade, lipídeos, proteínas, fibras e cinzas), segundo a metodologia descrita pela Association of Official Analytical Chemists - AOAC (1997).

As cultivares que apresentaram a maior porcentagem de lipídeos na polpa foram utilizadas para a determinação do perfil dos principais ácidos graxos presentes no óleo bruto extraído. Vinte frutos de cada uma das cultivares de abacateiro 'Hass' e 'Fuerte' passaram por prensagem hidráulica, das quais, por compressão, o óleo em seu estado bruto foi extraído. Em seguida, $5 \mathrm{~mL}$ do óleo obtido de cada cultivar foram esterificados segundo metodologia de HARTMAN \& LAGO (1973). A determinação da composição de ácidos graxos foi realizada por cromatografia de fase gasosa, utilizando-se cromatógrafo marca Shimadzu modelo GC-17A $\mathrm{V} 3$, equipado com detector de ionização de chama e coluna capilar de polietilenoglicol DB-Wax (30m 


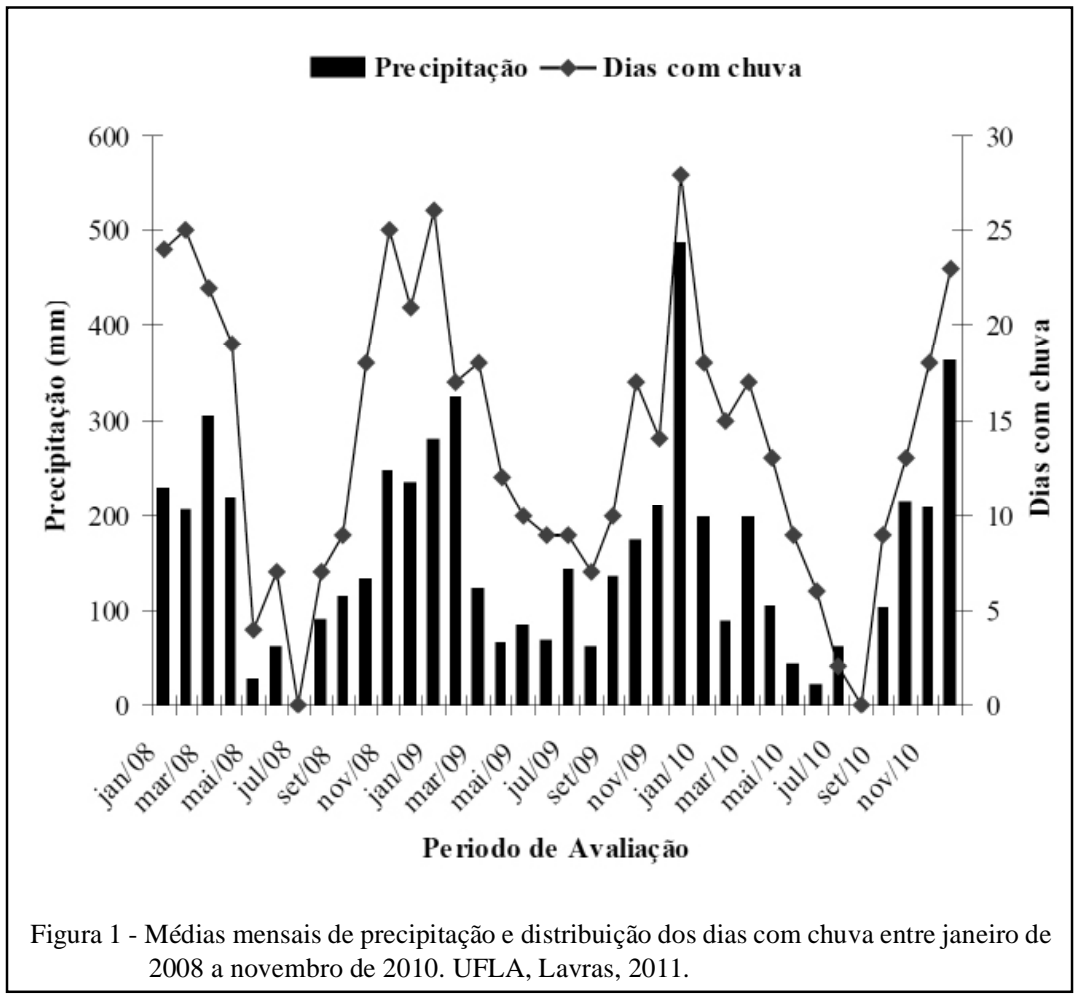

de comprimento; 0,25mm de diâmetro interno; 0,25 micrometro de espessura), Split na razão de 1:20.

As condições cromatográficas utilizadas foram: temperatura inicial da coluna igual a $180^{\circ} \mathrm{C}$ por 5 minutos, aumentada a uma taxa de $30^{\circ} \mathrm{C} \mathrm{min}^{-1}$ até a temperatura de $180^{\circ} \mathrm{C}$, permanecendo 14 minutos, até temperatura final da coluna de $230^{\circ} \mathrm{C}$ com aquecimento de $3^{\circ} \mathrm{C} \mathrm{min}^{-1}$. $\mathrm{O}$ gás de arraste usado foi o nitrogênio, em um fluxo de $2,74 \mathrm{~mL}$ minuto $^{-1}$. A temperatura do injetor foi $230^{\circ} \mathrm{C}$ e detector de $250^{\circ} \mathrm{C}$. A identificação dos diferentes ácidos graxos foi realizada por comparação entre os tempos de retenção das amostras e dos padrões. O delineamento experimental utilizado foi o inteiramente casualizado com dois tratamentos (cultivares de abacateiro 'Hass' e 'Fuerte', que apresentaram a maior porcentagem de lipídeos na polpa) e dez repetições (leituras).

Os dados referentes à caracterização físicoquímica e o perfil e ácidos graxos foram submetidos à análise de variância complementada pelo teste de Tukey e Scott-Knott para comparações múltiplas com nível de significância igual ou inferior a 5\%.

\section{RESULTADOS E DISCUSSÃO}

Pelas avaliações realizadas nos dois ciclos produtivos, todas as cultivares iniciaram a brotação a partir da segunda quinzena de setembro, sendo que Quintal e Campinas foram as mais tardias para o início da brotação (Tabela 1). O período de florescimento no ciclo 2008/09 teve início na segunda quinzena do mês de agosto estendendo-se até a segunda quinzena de outubro (Tabela 1). Já no ciclo de 2009/10, nota-se maior número de plantas iniciando o florescimento da segunda quinzena do mês de agosto até a primeira quinzena de outubro, com ciclo de floração variando entre 35 a 72 dias. Isso se dá provavelmente devido às diferenças nas variações climáticas ocorridas nos dois ciclos avaliados, já que em 2009, além das temperaturas mais elevadas, houve maior volume de chuvas nos meses que antecedem a floração (Figuras 1 e 2). Contudo, nos dois ciclos, observou-se que o mês de setembro concentrou o início da floração na maioria das cultivares avaliadas (Tabela 1).

Quanto ao término do período de floração, no primeiro ciclo de avaliação este ocorreu entre a primeira quinzena de outubro até o final de novembro, sendo que 'Margarida' mostrou-se mais precoce. No segundo ciclo avaliado, o final da floração ocorreu entre a segunda quinzena de outubro e novembro, com as cultivares 'Margarida', 'Reis' e 'Wagner' apresentando-se mais precoces (Tabela 1). Na média dos dois ciclos, o período de floração foi de 54 dias com os meses de setembro e outubro concentrando a plena

Ciência Rural, v.43, n.3, mar, 2013. 


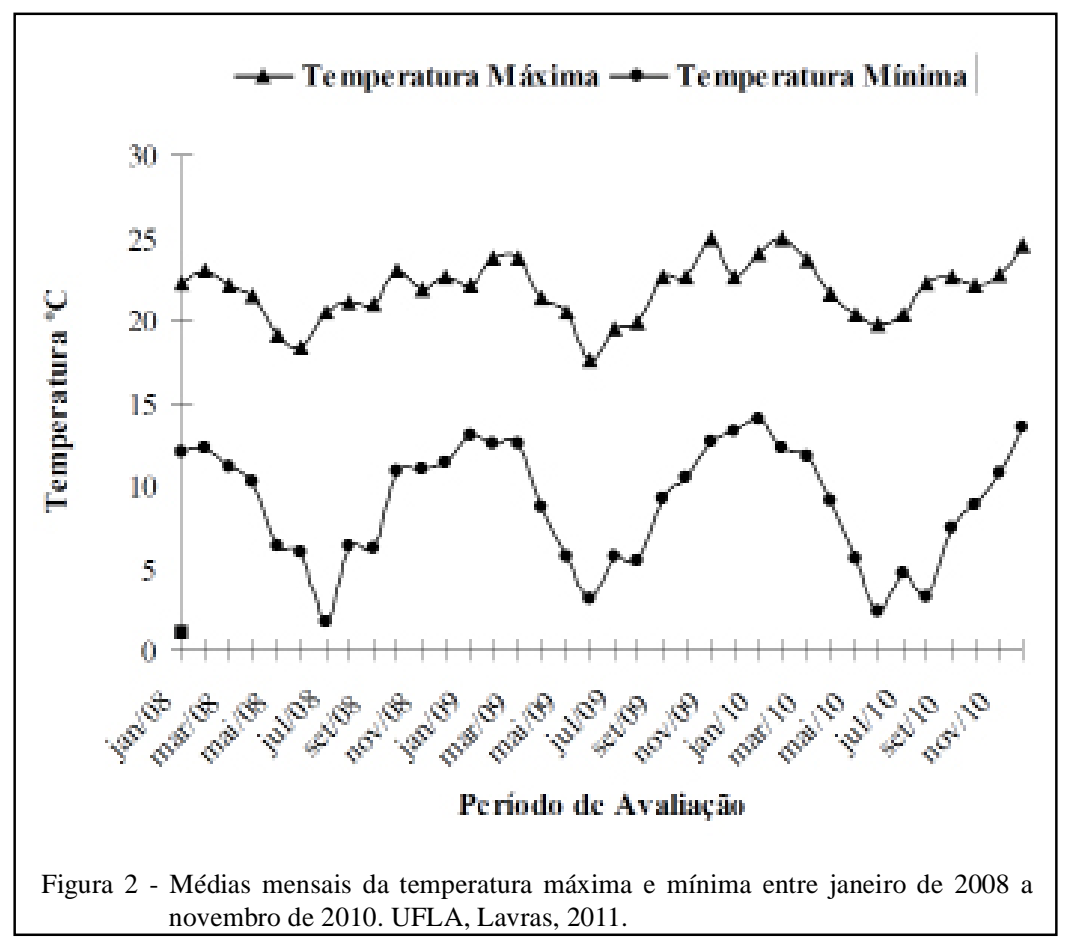

floração para todas as cultivares avaliadas. Segundo OLIVEIRA et al. (2012), o período de florescimento é influenciado pelas condições climáticas. AVILAN et al. (2009) verificaram que o período de floração variou entre 77 e 133 dias em abacateiros da raça antilhana, cultivados na região norte costeira da Venezuela. Já FALCÃO et al. (2001), trabalhando com abacateiro na Amazônia central, constataram o início do florescimento nos meses de abril a maio e no final entre setembro e outubro, concluindo que essa variação no padrão fenológico foi consequência das características genéticas de cada cultivar, de fenômenos climáticos como temperatura e fotoperíodo, os quais interferem na floração e brotação.

Nos dois ciclos de avaliação, o período de desenvolvimento dos frutos variou de 9 a 14 meses, em que a cultivar 'Ouro Verde' apresentou o menor período e a Fuerte o maior ciclo (Tabela 2). Esses resultados estão de acordo com os encontrados por COSSIO-VARGAS et al. (2008) que, trabalhando com a cultivar 'Hass', no México, verificaram ciclo de 11 meses entre o início da frutificação e a colheita. Para os dois ciclos avaliados, o período de colheita estendeu-se entre os meses de julho a novembro, com duração média de 17 dias; o maior período de colheita no primeiro ciclo foi de até 29 dias para Ouro Verde, Hass, Fortuna, Quintal e Margarida e, no segundo ciclo, até 26 dias para 'Fuerte' e 'Margarida' (Tabela 2), enquanto que o menor período de colheita foi obtido no segundo ciclo de avaliação, com até nove dias para as cultivares 'Pedroso' e 'Imperador'. A época de maturação das cultivares de abacate é variável em função da diversidade climática nas diferentes regiões (SENTELHAS et al., 1995). Isso se deve principalmente ao efeito da temperatura do ar sobre o desenvolvimento da planta, no período entre o florescimento e a maturação (Figuras 1 e 2).

$\mathrm{O}$ diâmetro longitudinal dos frutos variou em até $117 \%$, com as cultivares 'Hass' $(7,6)$ e 'Fuerte' $(8,9)$ apresentando os menores valores e Paulistinha $(18,5)$, Ouro Verde $(15,4)$, Reis $(14,3)$ e Quintal $(12,6)$ os maiores. Já o diâmetro transversal variou em até $62 \%$, apresentando diferença significativa apenas para a cultivar 'Hass' (Tabela 3). Os dados sobre as percentagens das porções polpa, casca e caroço nos frutos das diversas cultivares demonstram que o conteúdo variou entre $60,8 \%$ e $82,6 \%$ em relação à massa do fruto, tendo se destacado a cultivar 'Paulistinha' com maior proporção de polpa. A porção polpa é a mais relevante, pois constitui a parte comestível do fruto e de onde se extrai o lipídeo (TANGO et al., 2001). Esses resultados corroboram TANGO et al. (2004), os quais afirmaram que, mesmo as cultivares de abacateiro apresentando características distintas, como volume e massa dos frutos, houve menor dispersão nos valores da polpa. Ainda, segundo os mesmos autores, é fundamental para o processo de extração de óleo obter cultivares 
Tabela 1 - Grupo floral, datas de início da emissão das brotações, de início, do pleno e do final do florescimento e período de florescimento em cultivares de abacateiros nas safras 2008/2009 e 2009/2010. UFLA Lavras, 2011.

\begin{tabular}{|c|c|c|c|c|c|c|}
\hline Cultivar & GF & IB & IF & $\mathrm{PF}$ & $\mathrm{FF}$ & Período IF-FF (dias) \\
\hline 'Campinas' & $\mathrm{B}$ & $12 /$ out & 20/set & $10 /$ out & $30 /$ out & 40 \\
\hline 'Fortuna' & $A$ & $08 /$ out & 01/out & $25 /$ out & $25 / \mathrm{nov}$ & 55 \\
\hline 'Fuerte' & $\mathrm{B}$ & $21 /$ set & $03 /$ set & $27 /$ set & $20 /$ out & 47 \\
\hline 'Hass' & $A$ & $20 /$ set & 01/out & $15 /$ out & $10 / \mathrm{nov}$ & 40 \\
\hline 'Imperador' & $\mathrm{B}$ & $20 /$ set & $07 /$ set & $30 /$ set & $28 /$ out & 51 \\
\hline 'Margarida' & $\mathrm{B}$ & $27 /$ set & 18/ago & $12 /$ set & 13 /out & 56 \\
\hline 'Massaito' & $A$ & $10 /$ out & $15 /$ out & $30 /$ out & $20 /$ nov & 36 \\
\hline 'Ouro Verde' & A & $01 /$ out & $30 /$ set & $17 /$ out & $05 /$ nov & 36 \\
\hline 'Paulistinha' & $A$ & 30/set & $20 /$ set & $10 /$ out & $10 / \mathrm{nov}$ & 51 \\
\hline 'Pedroso' & $A$ & $07 /$ out & $01 /$ set & $28 /$ set & $20 /$ out & 49 \\
\hline 'Quintal' & $\mathrm{B}$ & $15 /$ out & $23 /$ set & $18 /$ out & $10 / \mathrm{nov}$ & 48 \\
\hline 'Reis' & $\mathrm{B}$ & $01 /$ out & $23 /$ set & $18 /$ out & $10 / \mathrm{nov}$ & 48 \\
\hline 'Wagner' & $A$ & $18 /$ set & 23/ago & $17 /$ set & 15 /out & 53 \\
\hline 'Campinas' & $\mathrm{B}$ & $05 /$ out & $10 /$ set & $30 /$ set & $25 /$ out & 45 \\
\hline 'Fortuna' & $\mathrm{A}$ & $25 /$ set & $30 /$ set & $19 /$ out & $10 / \mathrm{nov}$ & 41 \\
\hline 'Fuerte' & $\mathrm{B}$ & $10 /$ set & 30/ago & $14 /$ set & $21 /$ out & 52 \\
\hline 'Hass' & $\mathrm{A}$ & $15 /$ set & $25 /$ set & $12 /$ out & $30 /$ out & 35 \\
\hline 'Imperador' & $\mathrm{B}$ & $25 /$ set & $05 /$ set & $30 /$ set & $25 /$ out & 50 \\
\hline 'Margarida' & $\mathrm{B}$ & $25 /$ set & 20/ago & $10 /$ set & $05 /$ out & 46 \\
\hline 'Massaito' & $A$ & $05 /$ out & $10 /$ out & $28 /$ out & $13 / \mathrm{nov}$ & 34 \\
\hline 'Ouro Verde' & A & $25 /$ set & 20/set & $05 /$ out & 26/out & 36 \\
\hline 'Paulistinha' & $A$ & $05 /$ out & $15 /$ set & $05 /$ out & $24 /$ out & 39 \\
\hline 'Pedroso' & A & 30/set & 14/ago & $10 /$ set & 25/out & 72 \\
\hline 'Quintal' & $\mathrm{B}$ & $05 /$ out & $15 /$ set & 05/out & $25 /$ out & 40 \\
\hline 'Reis' & $\mathrm{B}$ & 20 /set & $10 /$ set & $30 /$ set & $18 /$ out & 38 \\
\hline 'Wagner' & $A$ & $25 /$ set & 20/ago & $15 /$ set & $10 /$ out & 51 \\
\hline
\end{tabular}

GF-Grupo Floral; IB-Início da Brotação; IF-Início do florescimento(5\% flores abertas); PF-Pleno florescimento(+ $70 \%$ flores abertas); FF-Final de florescimento; IF-FF-Periodo do florescimento (dias).

com menores percentagens de caroço e casca, tendo em vista o maior rendimento em polpa.

A análise da composição centesimal da polpa dos frutos mostra que os teores de umidade nas polpas variaram entre 60,97 e $81,92 \%$. Para os de lipídeos, a variação foi entre 5,7 e $26,12 \%$, e as cultivares 'Hass' e 'Fuerte' apresentaram resultados significativamente superiores às demais (Tabela 3 ). Nota-se, por esses resultados, um comportamento inverso nos conteúdos de lipídeos e umidade, em que as cultivares com melhores rendimentos em óleo apresentaram os menores índices de umidade e, portanto, maior potencial para a extração de óleo, inclusive para utilização na indústria alimentícia (GÓMEZ-LÓPES, 2002; SALGADO et al., 2008). Esses resultados estão de acordo com trabalho anteriormente realizado, em que as cultivares 'Hass' e 'Fuerte' se destacaram na percentagem de lipídeos na polpa (TANGO et al., 2004). Esses autores relatam ainda que a alta correlação entre umidade e lipídeos deve-se ao fato de que a soma dos teores dessas substâncias corresponde à grande parte da massa das polpas de abacate. Vale ressaltar que, ao contrário do consumidor brasileiro, o mercado externo preza por frutos menores e ricos em lipídeos; com isso, surge ainda a possibilidade de exportação de frutos ao natural destas cultivares (DAIUTO et al., 2010). O teor de proteína apresentou resultados em que o valor de $1,9 \%$ foi o máximo, obtido pela cultivar 'Hass', seguido da Campinas e Fuerte (Tabela 3). Estudos relatam que esse valor normalmente é baixo em frutas destinadas ao consumo humano (FARIA et al., 2008). É possível ainda inferir uma relação positiva para os teores de proteína e lipídeos, em que as cultivares

Ciência Rural, v.43, n.3, mar, 2013. 
Tabela 2 - Datas de início da frutificação, do início, final e duração de colheita e período de frutificação em cultivares de abacateiro nas safras 2008/09 e 2009/10. UFLA Lavras, 2011.

\begin{tabular}{|c|c|c|c|c|c|}
\hline Cultivar & IFR & $\mathrm{IC}$ & $\mathrm{FC}$ & IC-FC & Periodo IFR-FC (Dias) \\
\hline 'Campinas' & $20 /$ out & 28 /out & $17 /$ nov & 20 & 393 \\
\hline 'Fortuna' & $13 /$ out & 30/ago & $25 /$ set & 26 & 347 \\
\hline 'Fuerte' & $20 /$ set & $03 /$ nov & $23 /$ nov & 20 & 429 \\
\hline 'Hass' & $25 /$ set & $15 /$ out & $10 /$ nov & 26 & 411 \\
\hline 'Imperador' & $20 /$ set & $10 /$ set & $27 /$ set & 17 & 372 \\
\hline 'Margarida' & $13 /$ set & $25 /$ set & 20 /out & 25 & 402 \\
\hline 'Massaito' & $27 /$ out & $03 /$ set & $20 /$ set & 17 & 328 \\
\hline 'Ouro Verde' & 13 /out & 20/jul & 18/ago & 29 & 309 \\
\hline 'Paulistinha' & 05/out & $20 /$ set & $05 /$ out & 15 & 365 \\
\hline 'Pedroso' & 20 /set & $05 /$ set & $17 /$ set & 12 & 362 \\
\hline 'Quintal' & 05/out & $10 /$ ago & $05 /$ set & 26 & 335 \\
\hline 'Reis' & $18 /$ out & $10 /$ out & $23 /$ out & 13 & 370 \\
\hline "Wagner" & $10 /$ set & 10/ago & 21/ago & 11 & 345 \\
\hline 'Campinas' & $25 /$ set & 20/out & 08/nov & 19 & 409 \\
\hline 'Fortuna' & $10 /$ out & 30/ago & $18 /$ set & 19 & 387 \\
\hline 'Fuerte' & $10 /$ set & 25 /out & $18 /$ nov & 24 & 434 \\
\hline 'Hass' & $20 /$ out & 25/out & $10 /$ nov & 16 & 386 \\
\hline 'Imperador' & $15 /$ set & $13 /$ set & $22 /$ set & 9 & 372 \\
\hline 'Margarida' & $10 /$ set & $20 /$ set & $16 /$ out & 26 & 401 \\
\hline 'Massaito' & $20 /$ out & 30/ago & $12 /$ set & 13 & 327 \\
\hline 'Ouro Verde' & $30 /$ set & $30 /$ jul & $17 /$ ago & 18 & 321 \\
\hline 'Paulistinha' & $28 /$ set & $15 /$ set & $27 /$ set & 12 & 364 \\
\hline 'Pedroso' & $10 /$ set & $10 /$ set & $17 /$ set & 7 & 372 \\
\hline 'Quintal' & $30 /$ set & 15/ago & 29/ago & 14 & 397 \\
\hline 'Reis' & $14 /$ set & $15 /$ out & 03/nov & 19 & 415 \\
\hline 'Wagner' & $15 /$ set & 17/ago & $12 /$ set & 26 & 362 \\
\hline
\end{tabular}

IFR = Início da Frutificação; IC - Início da Colheita; FC-Final da Colheita; IC-FC = Período de Colheita (dias); IFR-FC- Período de Frutificação (dias).

com maiores quantidades lipídicas se destacaram. As quantidades de fibras variaram de 2,95 a $8,15 \%$, com as cultivares 'Paulistinha' e 'Hass' apresentando os maiores resultados (Tabela 3). Quanto ao teor de cinza, este se destacou superior na cultivar 'Hass' $(2,4 \%)$.

Diante dos resultados obtidos acima, procedeu-se à análise do perfil de ácidos graxos no óleo bruto extraído das cultivares 'Hass'e 'Fuerte'. Os resultados demonstraram altas percentagens de ácido oleico nas duas cultivares avaliadas, tendo Hass se destacado significativamente superior a Fuerte, com $64,74 \%$ contra $56,64 \%$ (Tabela 4). Já para o ácido palmítico, os resultados não apresentaram diferença significativa, porém, estão dentro do descrito por TANGO et al. (2004). Para ácido palmitoleico, a variação foi de $91,45 \%$ em suas concentrações, em que a cultivar 'Fuerte' se mostrou significativamente superior; para ácido esteárico, os valores encontrados foram quantidades traços de no máximo 0,34\% (Tabela 4). Para o ácido linoleico e linolênico, os valores encontrados apresentaram pouca variação entre as duas cultivares avaliadas. Pelos resultados obtidos, nota-se que as cultivares 'Hass' e 'Fuerte' apresentaram elevadas concentrações do ácido graxo oleico, o qual é rico em ômega 9.

Os resultados encontrados estão de acordo com trabalhos anteriores, nos quais foram constatados teores ao redor de $60 \%$ para os ácidos graxos ricos em ômega nove (TANGO et al., 2004). Os mesmos autores citam ainda que, em comparação com outras fontes de óleos vegetais, o óleo de abacate caracteriza-se por apresentar teores elevados de ácidos graxos monoinsaturados (oleico e palmitoleico), teor relativamente elevado do ácido 
Tabela 3 - Diâmetro longitudinal (DL), diâmetro transversal (DT), proporções dos componentes polpa, casca, caroço e composição centesimal (umidade, lipídeos, proteínas, fibra e cinza) em cultivares de abacateiro. UFLA, Lavras, 2011.

\begin{tabular}{|c|c|c|c|c|c|}
\hline Cultivar & $\mathrm{DL}(\mathrm{cm})^{*}$ & $\mathrm{DT}(\mathrm{cm})$ & Polpa (\%) & Casca $(\%)$ & Caroço(\%) \\
\hline 'Campinas' & $11,8 \mathrm{~b}$ & $9,0 \mathrm{ab}$ & $65,9 \mathrm{~d}$ & $15,4 \mathrm{bc}$ & $18,7 \mathrm{~d}$ \\
\hline 'Fortuna' & $10,9 \mathrm{~b}$ & $7,6 a b$ & $69,7 \mathrm{c}$ & $10,6 \mathrm{e}$ & $19,7 \mathrm{~d}$ \\
\hline 'Fuerte' & $8,9 \mathrm{c}$ & $6,6 \mathrm{ab}$ & $63,5 \mathrm{~d}$ & $12,1 d$ & $24,4 d$ \\
\hline 'Hass' & $7,6 \mathrm{~cd}$ & $5,9 \mathrm{~b}$ & $61,1 \mathrm{e}$ & $18,0 \mathrm{a}$ & $20,9 d$ \\
\hline 'Margarida' & $9,8 \mathrm{bc}$ & $9,4 a b$ & $70,8 \mathrm{bc}$ & $14,0 \mathrm{~cd}$ & $15,2 \mathrm{f}$ \\
\hline 'Ouro Verde' & $15,4 \mathrm{a}$ & $7,5 \mathrm{ab}$ & $70,9 b c$ & $14,9 \mathrm{c}$ & $14,2 \mathrm{f}$ \\
\hline 'Paulistinha' & $18,5 \mathrm{a}$ & $9,1 \mathrm{ab}$ & $82,6 a$ & $6,9 f$ & $10,5 f$ \\
\hline 'Pedroso' & $10,3 b$ & $8,4 a b$ & $64,2 \mathrm{~d}$ & $12,8 \mathrm{~d}$ & $23,0 \mathrm{c}$ \\
\hline 'Quintal' & $12,6 a b$ & $8,1 \mathrm{ab}$ & $67,5 \mathrm{c}$ & $9,3 \mathrm{e}$ & $23,2 \mathrm{c}$ \\
\hline 'Reis' & $14,3 \mathrm{a}$ & $9,4 a b$ & $71,4 b$ & $11,60 d$ & $17,0 \mathrm{e}$ \\
\hline 'Wagner' & $9,7 \mathrm{~b}$ & $7,6 a b$ & $60,8 \mathrm{e}$ & $11,30 \mathrm{~d}$ & $27,9 \mathrm{a}$ \\
\hline \multirow[t]{2}{*}{$\mathrm{CV}(\%)$} & 13,2 & 9,8 & 11,3 & 23,7 & 18,7 \\
\hline & Umidade $(\%)$ & Lipídeos $(\%)$ & Proteina $(\%)$ & Fibra $(\%)$ & Cinza $(\%)$ \\
\hline 'Campinas' & $75,29 \mathrm{c}$ & $2,19 \mathrm{~b}$ & $1,89 \mathbf{a}$ & $4,83 \mathrm{c}$ & $1,46 a b$ \\
\hline 'Fortuna' & $81,38 \mathrm{a}$ & $6,43 \mathrm{e}$ & $1,12 b$ & $4,24 c d$ & $1,00 \mathrm{~b}$ \\
\hline 'Fuerte' & $60,97 d$ & $26,12 \mathrm{a}$ & $1,88 \mathbf{a}$ & $4,72 \mathrm{c}$ & $1,30 \mathrm{~b}$ \\
\hline 'Hass' & $62,11 d$ & $21,07 \mathbf{a}$ & $1,90 \mathrm{a}$ & $7,14 b$ & $2,40 \mathrm{a}$ \\
\hline 'Margarida' & $81,20 \mathrm{a}$ & $8,74 d$ & $0,74 \mathrm{~b}$ & $2,95 \mathrm{e}$ & $0,81 b$ \\
\hline 'Ouro Verde' & $78,88 \mathrm{~b}$ & $8,45 d$ & $0,86 \mathrm{~b}$ & $4,13 \mathrm{c}$ & $0,94 \mathrm{~b}$ \\
\hline 'Paulistinha' & $76,88 \mathrm{~b}$ & $7,85 \mathrm{~d}$ & $1,20 \mathrm{~b}$ & $8,15 \mathbf{a}$ & $1,47 \mathrm{ab}$ \\
\hline 'Pedroso' & $81,05 b$ & $5,70 \mathrm{e}$ & $0,81 \mathrm{~b}$ & $4,25 \mathrm{c}$ & $0,84 b$ \\
\hline 'Quintal' & $75,20 \mathrm{c}$ & $10,95 \mathrm{c}$ & $1,14 b$ & $4,95 \mathrm{c}$ & $0,83 \mathrm{~b}$ \\
\hline 'Reis' & $81,92 \mathrm{a}$ & $9,29 \mathrm{~d}$ & $0,87 \mathrm{~b}$ & $2,96 \mathrm{~d}$ & $1,06 \mathrm{~b}$ \\
\hline 'Wagner' & $79,96 \mathrm{~b}$ & $9,44 d$ & $1,31 b$ & $3,31 d$ & $1,00 \mathrm{~b}$ \\
\hline $\mathrm{CV}(\%)$ & 1,40 & 17,36 & 2,37 & 9,23 & 36,39 \\
\hline
\end{tabular}

* Médias seguidas da mesma letra, na coluna, são iguais entre si pelo teste de Tukey em nível de $\mathbf{5 \%}$ de significància.

graxo saturado palmítico e menor conteúdo do ácido esteárico (saturado). Com isso, conclui-se que a composição em ácidos graxos é muito próxima ao azeite de oliva, principalmente quanto aos altos níveis de ácido oleico, já que os limites são de 55 a $83 \%$ no azeite de oliva (SILVA et al., 2012) e até mesmo da noz macadâmica (MARO et al., 2012).

Alguns autores citam ainda que a composição de ácidos graxos do óleo de abacate pode variar conforme a cultivar, estádio de maturação e localização geográfica de crescimento da planta (SENTELHAS et al., 1995). No entanto, o principal ácido graxo predominante sempre é o ácido oleico, seguido dos ácidos linoleico e palmítico (TANGO et al., 2004). Diante dos resultados obtidos, há possibilidade do estabelecimento de cultivos comerciais de abacateiros que apresentem altos teores de lipídeos na polpa ('Hass' e 'Fuerte'), sendo necessário o emprego de cultivares polinizadoras que possuam período de florescimento coincidente. Além disso, há necessidade de se avaliar o desempenho produtivo das cultivares promissoras selecionadas, aliando técnicas culturais que incrementem a produtividade por área.

\section{CONCLUSÃO}

O período de florescimento ocorreu entre agosto e novembro e de colheita de julho a novembro. Houve diferença na fenologia entre as cultivares, sendo que a cultivar 'Ouro Verde' foi a mais precoce e Fuerte, Campinas e Hass as mais tardias. Também se notou diferença entre os parâmetros físicoquímicos. Paulistinha e Reis apresentaram frutos de maior diâmetro longitudinal, sendo que a Paulistinha se destacou também com a maior porcentagem de polpa. Os maiores teores de lipídeos na polpa foram obtidos nas cultivares 'Fuerte' (26,12\%) e 'Hass' (21,07\%), com predomínio do ácido oleico nas amostras analisadas, sendo essas as duas cultivares recomendadas para a extração de óleo.

Ciência Rural, v.43, n.3, mar, 2013. 
Tabela 4 - Composição em porcentagem dos principais ácidos graxos presentes no óleo bruto de abacate. UFL,A, Lavras-MG, 2011.

\begin{tabular}{lccclcc}
\hline Cultivar & Palmítico* & Palmitoleico & Esteárico & Oleico & Linolêico & Linolênico \\
\hline 'Hass' & $8,21 \mathrm{a}$ & $5,15 \mathrm{~b}$ & $0,34 \mathrm{a}$ & $64,74 \mathrm{a}$ & $14,48 \mathrm{a}$ & $3,93 \mathrm{a}$ \\
'Fuerte' & $11,49 \mathrm{a}$ & $9,86 \mathrm{a}$ & $0,22 \mathrm{a}$ & $56,64 \mathrm{~b}$ & $14,19 \mathrm{a}$ & $2,45 \mathrm{a}$ \\
CV $(\%)$ & 15,70 & 8,45 & 34,54 & 4,76 & 6,23 & 28,74 \\
\hline
\end{tabular}

* Médias seguidas da mesma letra, na coluna, são iguais entre si pelo teste de Scott-Knott em nivel de $5 \%$ de significância.

\section{AGRADECIMENTOS}

Os autores agradecem ao apoio da Coordenadoria de Assistência Técnica Integral (CATI), Conselho Nacional de Desenvolvimento Científico e Tecnológico (CNPq), Fundação de Amparo à Pesquisa do Estado de Minas Gerais (FAPEMIG), pelas contribuições estruturais e financeiras prestadas ao desenvolvimento deste trabalho.

\section{REFERÊNCIAS}

AOAC (ASSOCIATION OF OFFICIAL ANALYTICAL CHEMISTS). Official methods of analysis of the association of official analytical chemistry. 16ed. Washington, 1997. V.2.

AVILAN, L. et al. Comportamiento fenológico de la raza antillana de aguacate en la región centro-norte costera de Venezuela. Agronomía Tropical, v.59, n.1, p.5-14, 2009.

COSSIO-VARGAS, L.E. et al. Fenología del aguacate 'Hass' en el clima semicálido de Nayarit, México. Revista Chapingo, v.14, n.3, p.319-324, 2008.

DAIUTO, E.R. et al. Estabilidade físico-química de um produto de abacate acondicionado em diferentes embalagens e conservado pelo frio. Alimentos Nutrição, v.21, n.1, p.99-107, 2010.

FALCÃO, M.A. et al. Fenologia e produtividade do abacate (Persea Americana Mill.) na Amazônia Central. Acta Amazônica, v.31, n.1, p.3-9, 2001.

FARIA, J.P. et al. Caracterização da polpa do coquinhoazedo (Butia capitata var capitata). Revista Brasileira de Fruticultura, v.30, n.3, p.827-829, 2008. Disponível em: $<$ http://www.scielo.br/scielo.php?script=sci_arttext\&pid=S0100$29452008000300045 \& \operatorname{lng}=\mathrm{pt} \& \mathrm{nrm}=\mathrm{iso} \& \mathrm{t} \operatorname{lng}=\mathrm{pt}>$. Acesso em: 08 set. 2011. doi: 10.1590/S0100-29452008000300044.

GÓMEZ-LÓPES, V.M. Caracterização de frutos de cultivares de abacate com alto teor de óleo. Sciencia Agrícola, v.59, n.2, p.403-406, 2002. Disponível em: <http://www.scielo.br/scielo. php?script=sci_arttext \&pid=S0103-90162002000200030\&lng=p t\&nrm=iso\&tlng=en>. Acesso em: 08 set. 2011. doi: 10.1590/ S0103-90162002000200030.
HARTMAN, L.; LAGO, R.C. Rapad preparation of fatty acid methyl esters from lipids. Laboratory Practice, v.22, n.6, p.475476, 1973.

IBGE (INSTITUTO BRASILEIRO DE GEOGRAFIA E ESTATÍSTICA). Produção agrícola municipal. Disponível em: <http://www.ibge.gov.br>. Acesso em: 22 nov. 2012.

MARO, L.A.C. et al. Caracterização química e perfil de ácidos graxos em cultivares de nogueira-macadâmia. Ciência Rural, v.42, n.12, p.2166-2171, 2012.

OLIVEIRA, M.C. et al. Características fenológicas e físicas e perfil de ácidos graxos em oliveiras no sul de Minas Gerais. Pesquisa Agropecuária Brasileira, v.47, n.11, p.30-35, 2012. Disponível em: <http://www.scielo.br/scielo.php?script=sci arttext\&pid=S0100-204X2012000100005\&lng=pt\&nrm=iso $\&$ tlng $=\mathrm{pt}>$. Acesso em: 22 nov. 2012. doi: 10.1590/S0100204X2012000100005.

SALGADO, J.M. et al. O óleo de abacate (Persea americana Mill) como matéria-prima para a indústria alimentícia. Ciência e Tecnologia deAlimentos, v.28, supl, p.20-26, 2008. Disponível em: $<$ http://www.scielo.br/scielo.php?script=sci_arttext\&pid=S0101$20612008000500004 \& \operatorname{lng}=\mathrm{pt} \& \mathrm{nrm}=\mathrm{iso} \& \operatorname{lng}=\mathrm{pt}>$. Acesso em: 08 set. 2011. doi: 10.1590/S0101-20612008000500004.

SENTELHAS, P.C. et al. Zoneamento climático da época de maturação do abacate no estado de São Paulo. Revista Brasileira de Agrometeorologia, v.3, p.133-140, 1995.

SILVA, L.F.O. et al. Variação na qualidade do azeite em cultivares de oliveira. Bragantia, v.71, n.2, p.202-209, 2012. Disponível em: <http://www.scielo.br/scielo.php?script=sci_arttext\&pid=S0006$87052012000200008 \& \operatorname{lng}=\mathrm{pt} \& \mathrm{nrm}=\mathrm{iso} \& \operatorname{lng}=\mathrm{pt}>$. Acesso em: 23 out. 2012. doi: 10.1590/S0006-87052012000200008.

TANGO, J.S. et al. Caracterização física e química de frutos de abacate visando a seu potencial para extração de óleo. Revista Brasileira de Fruticultura, v.26, n.1, p.17-23, 2004. Disponível em: <http://www.scielo.br/scielo.php?script=sci_ arttext\&pid=S0100-29452004000100007\&lng=pt\&nrm $=$ iso $\&$ tlng $=\mathrm{pt}>$. Acesso em: 08 set. 2011. doi: 10.1590/S010029452004000100007. 